\title{
Regulation of P-Glycoprotein in Renal Proximal Tubule Epithelial Cells by LPS and TNF- $\alpha$
}

\author{
Suzanne Heemskerk, ${ }^{1,2}$ Janny G. P. Peters, ${ }^{1}$ Jochem Louisse, ${ }^{1}$ Seil Sagar, ${ }^{1}$ Frans G. M. Russel, ${ }^{1}$ \\ and Rosalinde Masereeuw ${ }^{1}$ \\ ${ }^{1}$ Department of Pharmacology and Toxicology, Nijmegen Medical Centre, Radboud University, \\ Nijmegen Centre for Molecular Life Sciences, P.O. Box 9101, 6500 HB Nijmegen, The Netherlands \\ ${ }^{2}$ Department of Intensive Care Medicine, Nijmegen Medical Centre, Radboud University, 6500 HB Nijmegen, The Netherlands
}

Correspondence should be addressed to Rosalinde Masereeuw, r.masereeuw@pharmtox.umcn.nl

Received 2 July 2009; Revised 13 November 2009; Accepted 8 December 2009

Academic Editor: Xue-Ru Wu

Copyright (C) 2010 Suzanne Heemskerk et al. This is an open access article distributed under the Creative Commons Attribution License, which permits unrestricted use, distribution, and reproduction in any medium, provided the original work is properly cited.

During endotoxemia, the ATP-dependent drug efflux pump P-glycoprotein (Abcb1/P-gp) is upregulated in kidney proximal tubule epithelial cells. The signaling pathway through which lipopolysaccharide (LPS) or tumor necrosis factor- $\alpha$ (TNF- $\alpha$ ) regulates P-gp expression and activity was investigated further in the present study. Exposure of rat kidney proximal tubule cells to TNF- $\alpha$ alone or TNF- $\alpha$ and LPS increased P-gp gene and protein expression levels and efflux activity, suggesting de novo P-gp synthesis. Upon exposure to TNF- $\alpha$ in combination with LPS, P-gp activity in renal proximal tubule cells is increased under influence of nitric oxide (NO) produced by inducible NO synthase. Upon exposure to TNF- $\alpha$ alone, P-gp upregulation seems to involve TLR4 activation and nuclear factor kappaB (NF- $\kappa \mathrm{B})$ translocation, a pathway that is likely independent of NO. These findings indicate that at least two pathways regulate P-gp expression in the kidney during endotoxemia.

\section{Introduction}

P-glycoprotein (Abcb1/P-gp) is a member of the ATP binding cassette $(\mathrm{ABC})$ superfamily and is able to transport a broad range of uncharged and cationic compounds. The apical localization of P-gp in renal proximal tubule epithelial cells is consistent with its importance in excretory transport into urine [1]. In agreement with the detoxifying role of P-gp, we recently found an upregulation of P-gp in rat kidney during endotoxemia [2] and in mouse kidney after ischemia reperfusion injury [3]. P-gp is likely to be regulated by nitric oxide (NO) produced by renal inducible $\mathrm{NO}$-synthase (iNOS), because co-administration of an iNOS-inhibitor attenuated the endotoxin-induced effects on its expression in rats [2]. An upregulation of important efflux pumps, like Pgp, may diminish the accumulation of toxic compounds and serves a protective function in acute kidney injury.

Using killifish renal proximal tubules, we found previously that $\mathrm{NO}$ has a regulatory role in the transport activity of multidrug resistance protein $2(A b c c 2 / \mathrm{Mrp} 2)$ via an intracellular signaling pathway in response to the in vitro action of several nephrotoxic chemicals [4]. This pathway involved at least endothelin (ET) release, binding to the basolateral $\mathrm{ET}_{\mathrm{B}}$ receptor, and activation of NOS, soluble guanylyl cyclase (sGC) and protein kinase C (PKC) [5]. A similar regulatory pathway was found for P-gp in rat brain capillaries [6], where it was recently shown to be correlated with an innate immune response $[7,8]$. The inflammatory mediator, tumor necrosis factor-alpha (TNF- $\alpha$ ) signalled through the TNF-receptor 1 (TNFR1) to increase P-gp expression and transport activity by triggering the ET-NOSPKC pathway, finally activating the nuclear factor kappaB, NF- $\kappa$ B [7].

As NF- $\kappa$ B was previously shown to be involved in P-gp increase during renal toxicity $[2,3,9]$, we hypothesized that the same signaling pathway is responsible for the upregulation of P-gp in the kidney during endotoxemia and that NO is the central player in the field. To test this hypothesis, we used a spontaneously immortalized rat kidney proximal tubular cell line and determined P-gp expression and activity 
after treating cells with endotoxin (lipopolysaccharide; LPS) or the most important pro-inflammatory cytokine, TNF$\alpha$. Our findings indicate that exposure to TNF- $\alpha$ in combination with LPS increases P-gp activity in renal proximal tubule cells under influence of NO produced by iNOS. Upon exposure to TNF- $\alpha$ alone, P-gp upregulation seems to involve TLR4 activation and NF- $\kappa \mathrm{B}$ translocation, a pathway that is likely independent of NO. These findings indicate that at least two different pathways regulate P-gp expression during endotoxemia.

\section{Materials and Methods}

2.1. Chemicals. Dulbecco's modified eagle's medium (DMEM), Hanks' balanced salt solution (HBSS), insulintransferrin-selenium, and TRIzol reagent were from Invitrogen Life Sciences (Breda, The Netherlands), fetal calf serum from MP Biomedicals (Asse-Relegum, Belgium), 4(2-hydroxyethyl)-1-piperazine ethanesulfonic acid (Hepes) from Roche diagnostics (Almere, the Netherlands), calceinacetoxymethylester (calcein-AM) from Molecular Probes (Eugene, OR), bisindolylmaleimide (BIM, Bruschwig chemie, Amsterdam, the Netherlands), H398 from Alexis (Lausen, Switzerland), antihuman Toll-like receptor (TLR)4 CD284/MD complex from Biolegend (San Diego, USA), and $1 \mathrm{H}-[1,2,4]$ oxadiazolo $[4,3,-a]$ quinoxalin-1-one (ODQ) and SN50 from Calbiochem (Nottingham, U.K.). The P-gp inhibitor, PSC-833, was a gift from Novartis Pharma (Valspodar, Arnhem, The Netherlands). All other chemicals were of analytical grade and purchased from Sigma-Aldrich (Zwijndrecht, The Netherlands) or Merck (Darmstadt, Germany).

2.2. Cell Culture and Analysis of P-gp Transport Activity. The spontaneously immortalized epithelial cell line isolated from rat kidney proximal tubule (GERP cells) was a kind gift of the department of Veterinary Pharmacology, Pharmacy and Toxicology of the University of Utrecht, The Netherlands. These cells (passages 53201374) were cultured in collagen coated culture flasks in DMEM supplemented with 5\% fetal calf serum and $1 \%$ insulin-transferrin-selenium. We previously demonstrated that P-gp activity in these cells was highest just after reaching confluency and decreased with culturing time [10]. Cells were plated at a density of 40,00060,000 cells/well for 3 days in a 24-well plate.

Culture medium was replaced for medium alone (control group) or medium supplemented with the tested compounds: lipopolysaccharide $\quad(10-100 \mu \mathrm{g} / \mathrm{mL}$ LPS, Escherichia coli 0127:B8), or TNF- $\alpha(1-100 \mathrm{ng} / \mathrm{mL})$, or the NO-donor sodium nitroprusside (0.1-0.5 mM SNP), or to a combination of LPS and TNF- $\alpha$, with the NO-scavenger 2-phenyl-4,4,5,5-tetramethylimidazoline-1-oxyl 3-oxide (0.01-0.5 mM PTIO). The concentration TNF- $\alpha$ relates to plasma levels that can be reached in patients with septic conditions [11]. Cells were also exposed to TNF- $\alpha$ in combination with an inhibitor of sGC, ODQ, (0.01 mM), an inhibitor of PKC, BIM, (100 nM), an inhibitor of TNFR1, H398, $(10 \mu \mathrm{g} / \mathrm{mL})$, the anti-human TLR4, CD284)/MD complex, $(5 \mu \mathrm{g} / \mathrm{mL})$, the selective I kappa B kinase (IKK) $\beta$ inhibitor, IMD-0354, $(10-50 \mu \mathrm{M})$, or the peptide inhibitor for NF- $\kappa \mathrm{B}$ nuclear translocation SN50 (1-1.8 $\mu \mathrm{M})$.

After treatment the transport activity of P-gp was determined with the calcein accumulation assay [12], as previously described [10]. The activity was determined by calculating the ratio of cellular accumulation of fluorescent calcein in the presence and absence of the P-gp inhibitor, PSC 833 , and control cells were set to $100 \%$.

2.3. Determination of $m R N A$ Expression. Cells were exposed to medium (control), LPS, TNF- $\alpha$ or to a combination of LPS and TNF- $\alpha$ for various time periods $(2,6,24$ hours) and were, subsequently, harvested for RNA isolation (for 5 minutes at $1300 \mathrm{~g}$ at room temperature). Cell pellets were transferred in ice cold TRIzol reagent (Invitrogen, Breda, the Netherlands) and RNA was isolated as described previously [13]. Quantitative Real Time-PCR (RQPCR) on cDNA was performed according to the TaqMan protocol in optical tubes using either the ABI PRISM 7700 single reporter Sequence Detection System $(n=$ 6, Applied Biosystems, Zwijndrecht, The Netherlands) or the ABI PRISM 7900HT Gene Expression Micro Fluidic Card Sequence Detection System (3 pooled samples from 9 different rats, Applied Biosystems) according to the manufacturer's instructions. All experiments were performed in triplicate. In rodents, two genes ( $A b c b 1 a$ and $A b c b 1 b)$ encode for P-gp, however, during endotoxemia only $A b c b 1 b$ was found to be differentially expressed [2]. Different rat genes (GAPDH: (Rn99999916_S1), Abcb1b: (Rn00561753_m1), NOSII: (Rn00561646_m1), or Ednrb/endothelin receptor $B$ : Rn00569139_m1) were amplified with a pre-developed Gene Expression Assay, provided by Applied Biosystems. The relative expression of genes in control cells were normalized for the average cycle threshold $\left(C_{T}\right)$ value for the housekeeping gene, GAPDH $\left(C_{T}=15.9 \pm 1.0\right)$ and set to 1 .

For the analysis of TNF- $\alpha$ receptor 1 (TNFR1), TNFR2, and toll-like receptor-4 (TLR4) mRNA expression in GERP cells exposed for 24 hours to TNF- $\alpha$, PCR amplification was performed as previously described [14]. Gene-specific primers were purchased from Biolegio (Nijmegen, The Netherlands): rat TNFR1 (M63122; nt.983-1382), forward primer: gggattcagctcctgtcaaa, reversed primer (atgaactccttccagcgtgt; (M63122, nt.704-1902) forward primer: tcccctgtaaggagaaacagaa, reversed primer: gctttttctccacaatcacctc [15]. Rat TNFR2: (AF498039, nt. 579-1034), forward primer: gttctctgacaccacatcatcc, reversed primer: gtcaataggtgctgctgttcaa; (AF498039, nt.541-1242), forward primer: aatggaaacgtgatatgcagtg, reversed primer: gctacagacgttcacgatgc [15]. Rat TLR4: (NM_019178, nt.2418-2546), forward primer: gagccggaaagttattgtgg, reversed primer: agcaaggacttctccactttct [16]. Rat $\beta$-actin: forward primer: ctatgagctgctgacggtc, reversed primer: agtttcatggatgccacagg [14]. The expected PCR products are: TNFR1-primer set 1: $400 \mathrm{bp}$, TNFR1-primer set 2: $1199 \mathrm{bp}$, TNFR2-primer set 1: $456 \mathrm{bp}$, TNFR2-primer set 2: 702 bp, TLR4: $129 \mathrm{bp}$. MilliQ was used as a negative control. The expression of the housekeeping gene $\beta$-actin was measured as a control for the performed PCR reaction. 




(a)

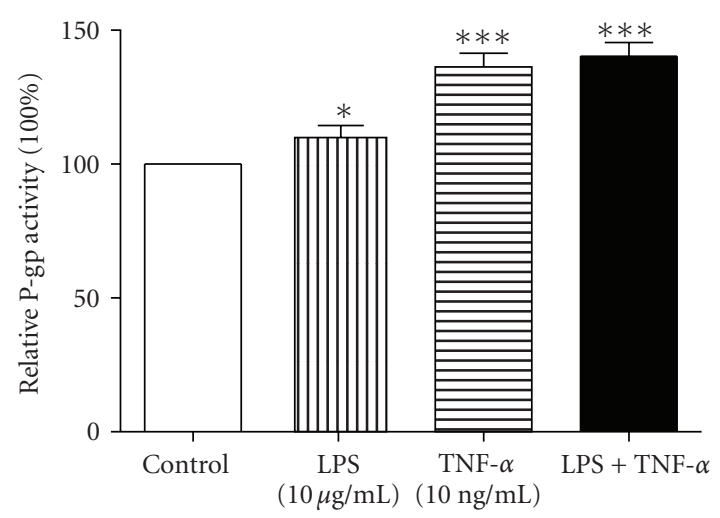

(c)

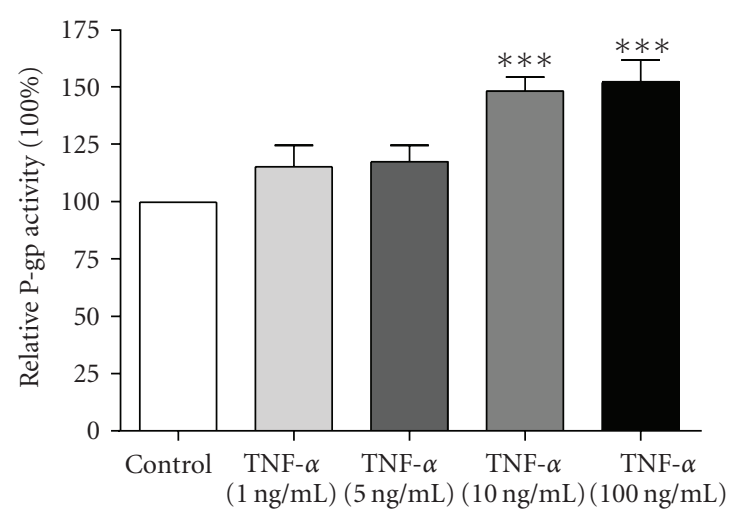

(b)

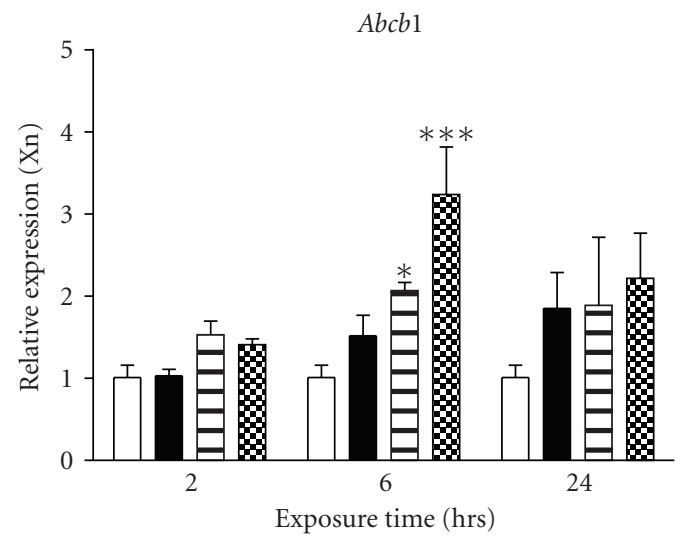

(d)
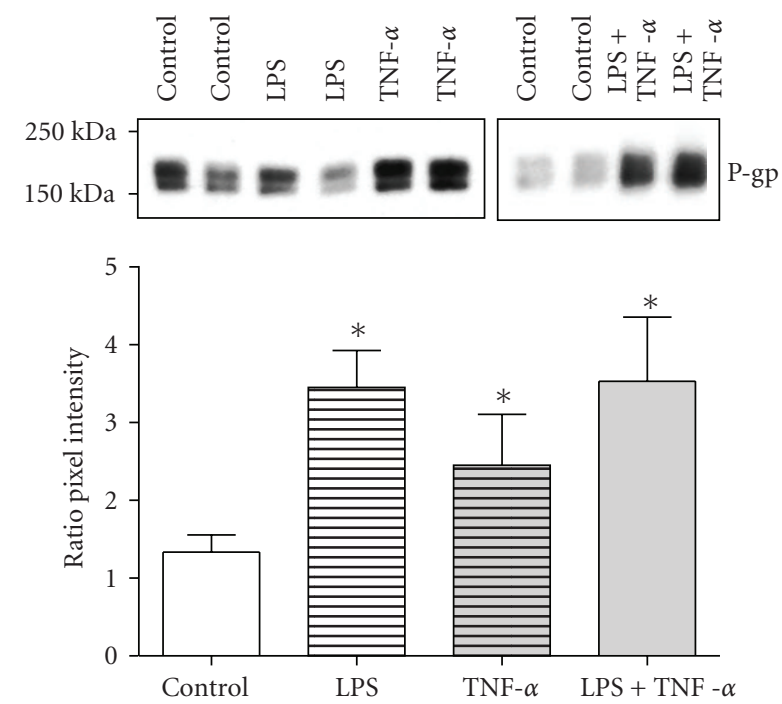

(e)

FIGURE 1: P-gp activity and expression after exposure to TNF- $\alpha$ and/or LPS in GERP cells. (a)-(c) P-gp transport activity in GERP cells after exposure to different concentrations of TNF- $\alpha((\mathrm{a}) n=4-6)$ or LPS ((b) $n=4)$ for 24 hours compared to control (cells exposed to culture medium). ((c) $n=12$ ) Optimal concentrations of both sepsis mediators were used for exposure to GERP cells for 24 hours. P-gp activity was determined using the calcein accumulation assay. ((d) $n=4) A b c b 1 b$ expression in GERP cells (control; open bars) after exposure to either $10 \mu \mathrm{g} / \mathrm{mL}$ LPS (closed bars), $10 \mathrm{ng} / \mathrm{mL}$ TNF- $\alpha$ (striped bars) or both $10 \mu \mathrm{g} / \mathrm{mL}$ LPS and $10 \mathrm{ng} / \mathrm{mL}$ TNF- $\alpha$ (chequered bars) for 2,6 or 24 hours. mRNA levels were determined with RQ-PCR and expression was normalized for the GAPDH $C_{T}$ value $(15.9 \pm 1.0)$. ((e) $\left.n=4\right)$ P-gp protein expression in GERP cells (control; lanes 1, 2, 7 and 8) after exposure to either $10 \mu \mathrm{g} / \mathrm{mL}$ LPS (lanes 3 and 4), $10 \mathrm{ng} / \mathrm{mL}$ TNF- $\alpha$ (lanes 5 and 6) or to both $10 \mu \mathrm{g} / \mathrm{mL}$ LPS and $10 \mathrm{ng} / \mathrm{mL}$ TNF- $\alpha$ (lanes 9 and 10) for 24 hours. Total cell lysate fractions of GERP cells were used and expression of P-gp was determined by Western blotting. Relative pixel intensities (ratio P-gp/ $\beta$-actin) were determined through image analysis. Data are expressed as mean \pm SEM. Significantly different compared to control cells $(*: P<.05, * * *: P<.001)$. 


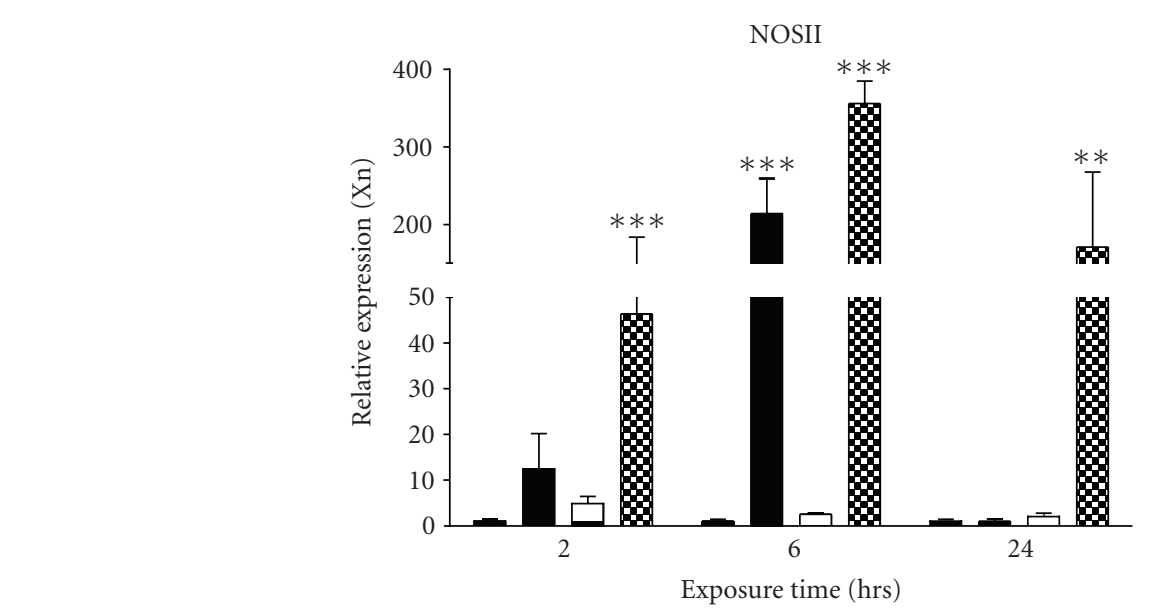

(a)

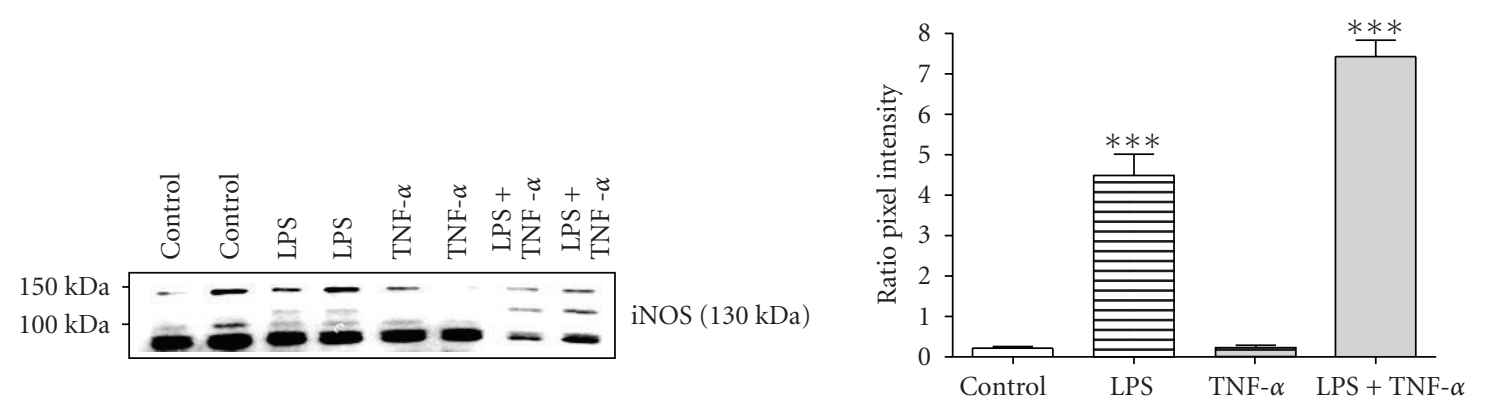

(b)

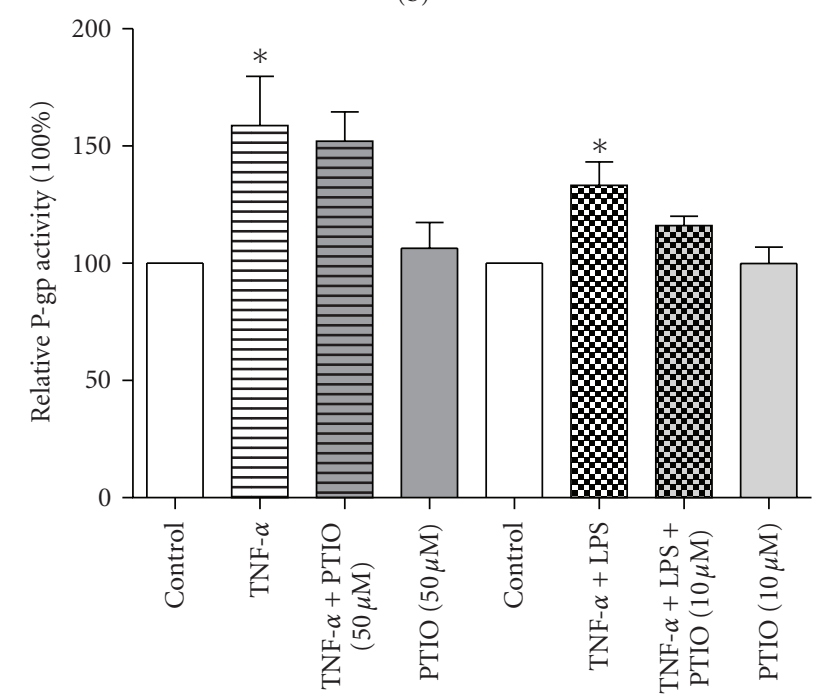

(c)
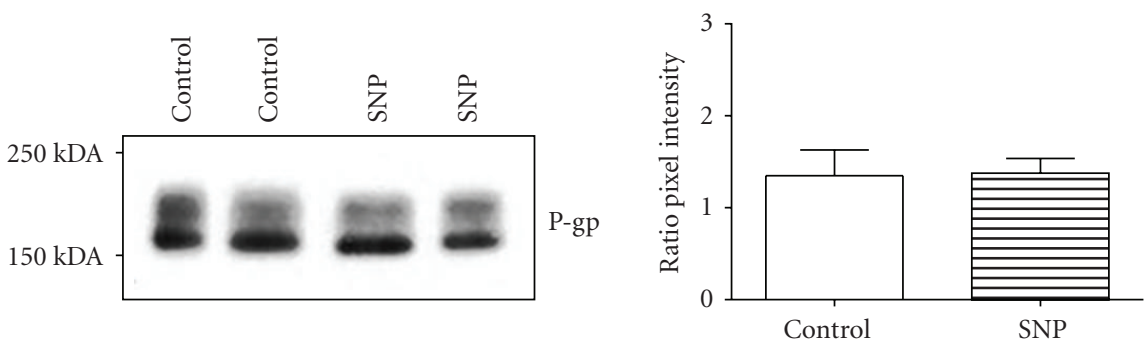

(d)

Figure 2: Continued. 


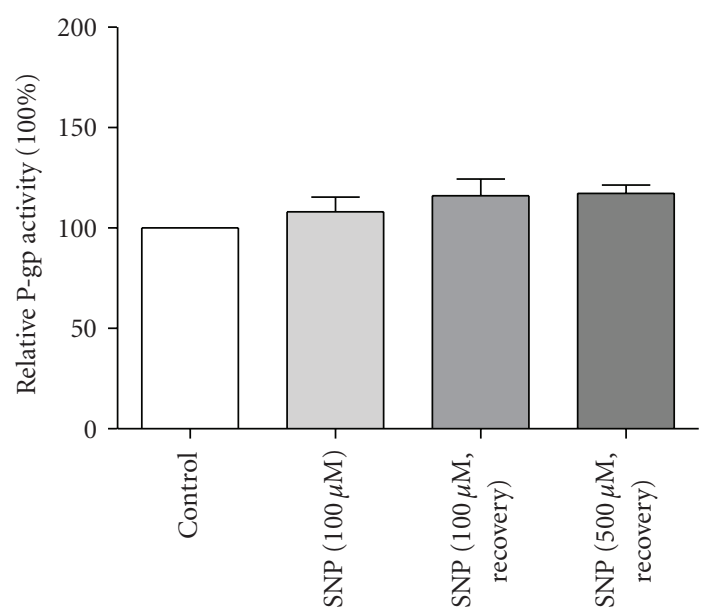

(e)

FIgURE 2: Expression of iNOS and effect of NO on Abcb1/P-gp activity in GERP cells. ((a) $n=4)$ NOSII expression in GERP cells after exposure to either $10 \mu \mathrm{g} / \mathrm{mL}$ LPS (closed bars), $10 \mathrm{ng} / \mathrm{mL}$ TNF- $\alpha$ (striped bars) or both $10 \mu \mathrm{g} / \mathrm{mL}$ LPS and $10 \mathrm{ng} / \mathrm{mL}$ TNF- $\alpha$ (chequered bars) for 2, 6 or 24 hours $(n=4)$. mRNA levels were determined with RQ-PCR and expression was normalized for the GAPDH $C_{T}$ value. ((b) $n=4$ ) iNOS protein expression in GERP cells (control; lanes 1 and 2) after exposure to either $10 \mu \mathrm{g} / \mathrm{mL}$ LPS (lanes 3 and 4 ), $10 \mathrm{ng} / \mathrm{mL}$ TNF- $\alpha$ (lanes 5 and 6) or both $10 \mu \mathrm{g} / \mathrm{mL}$ LPS and $10 \mathrm{ng} / \mathrm{mL}$ TNF- $\alpha$ (lanes 7 and 8 ) for 6 hours. ((c) $n=3-5$ ) P-gp transport activity in GERP cells after exposure to $10 \mathrm{ng} / \mathrm{mL}$ TNF- $\alpha$ or both $10 \mu \mathrm{g} / \mathrm{mL}$ LPS and $10 \mathrm{ng} / \mathrm{mL}$ TNF- $\alpha$ in combination with 50 or $10 \mu \mathrm{M}$ of the NO-scavenger PTIO, respectively, for 24 hours compared to control (cells exposed to culture medium). ((d) $n=4)$ P-gp protein expression in GERP cells (control; lanes 1 and 2) after exposure to $100 \mu \mathrm{M}$ SNP (lanes 3 and 4 ) for 1 hour with 5 hours recovery. ((e) $n=4)$ P-gp transport activity in GERP cells, compared control, after exposure to 100 or $500 \mu \mathrm{M}$ SNP for 6 hours or for 1 hour with a subsequent recovery period of 5 hours. Total cell fractions of GERP cells were used and expression of iNOS (b) or P-gp (d) was determined by Western blotting. Relative pixel intensities (ratio iNOS/ $\beta$-actin $(\mathrm{b})$ and ratio P-gp/ $\beta$-actin $(\mathrm{d})$ ) were determined through image analysis. Data are expressed as mean \pm SEM. Significantly different compared to control $\left({ }^{*}: P<.05,{ }^{* *} ; P<.01,{ }^{* * *}: P<.001\right)$.

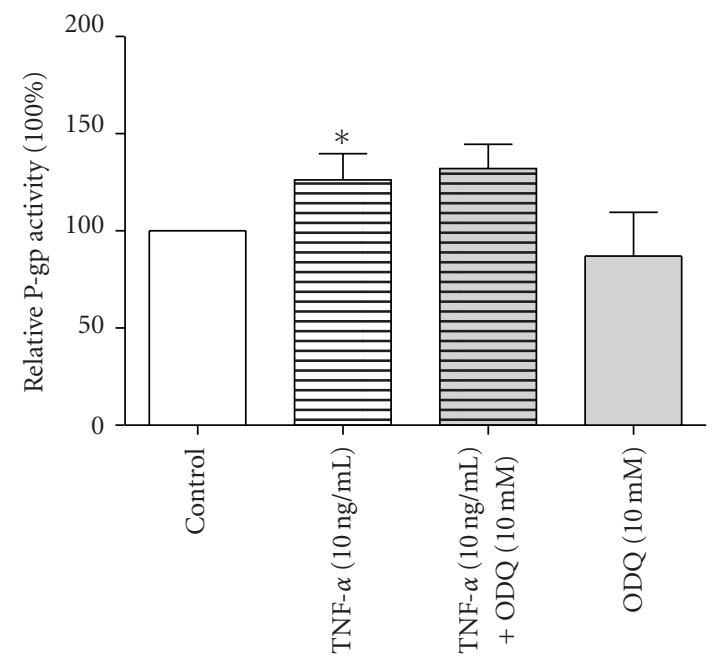

(a)

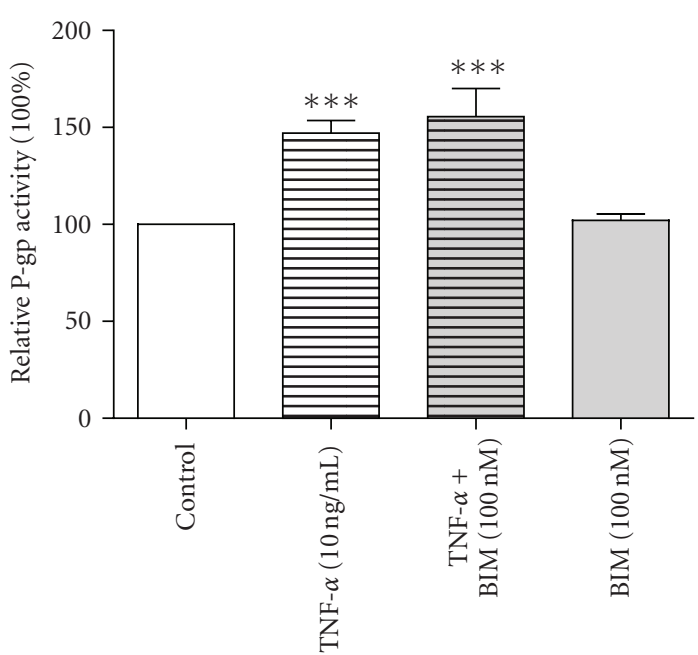

(b)

FIGURE 3: Lack of involvement of cGMP and PKC in P-gp regulation. ((a) $n=3-6)$ P-gp transport activity in GERP cells after exposure to $10 \mathrm{ng} / \mathrm{mL}$ TNF- $\alpha$ in combination with $10 \mu \mathrm{M}$ of the sGC inhibitor ODQ for 24 hours compared to control (cells exposed to culture medium). ((b) $n=3)$ P-gp transport activity in GERP cells after exposure to $10 \mathrm{ng} / \mathrm{mL}$ TNF- $\alpha$ in combination with $100 \mathrm{nM}$ of the PKC inhibitor BIM for 24 hours compared to control. Data are expressed as mean \pm SEM. Significantly different compared to control $\left({ }^{*}: P<.05 ;{ }^{* * *}: P<.001\right)$. Treatment with ODQ or BIM alone showed no significant difference compared to control. 




(a)

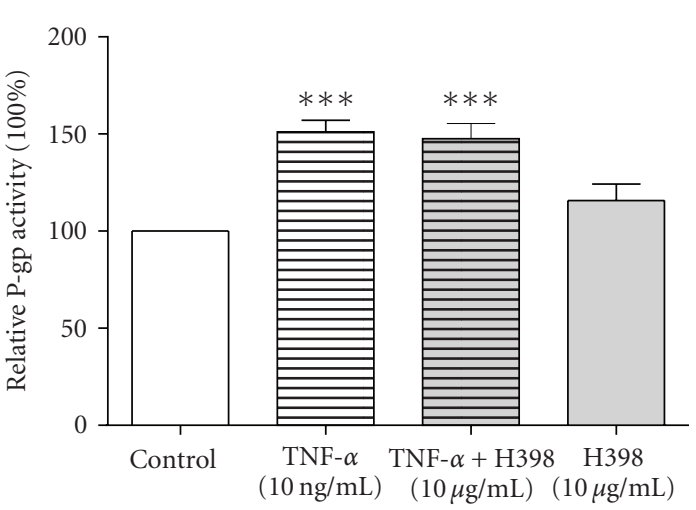

(b)

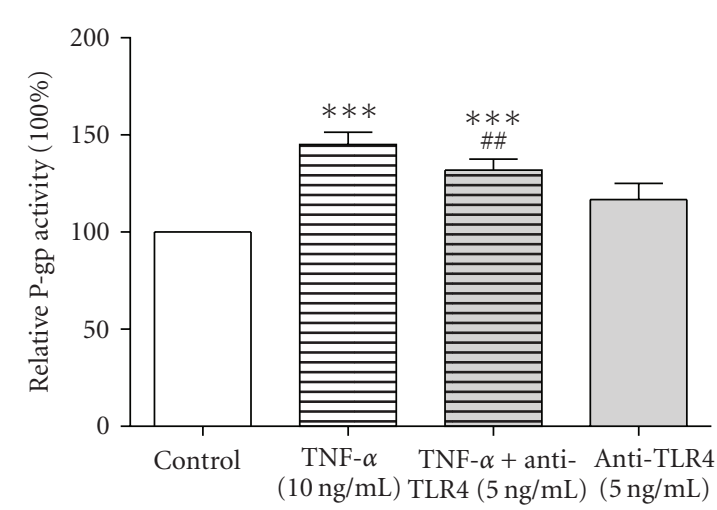

(c)

FIgURE 4: Role of TNF receptors and toll-like receptor 4 in modulation of P-gp activity in GERP cells. (a) TNFR1, TNFR2 and TLR4 mRNA expression was analyzed in GERP cells (control; lane 1 and 2) exposed for 24 hours to TNF- $\alpha$ (lanes 3 and 4 ) using PCR. For TNFR1 and TNFR2 two different primer sets were used, for TLR4 only one primer set was used. MilliQ (MQ) was used as a negative control. For both experiments the expression of the housekeeping gene $\beta$-actin was performed as a control for the performed PCR reaction. ((b) $n=3) \mathrm{P}$-gp transport activity in GERP cells after exposure to $10 \mathrm{ng} / \mathrm{mL}$ TNF- $\alpha$ in combination with $10 \mathrm{mg} / \mathrm{mL}$ of the TNFR1 inhibitor H398 for 24 hours compared to control (cells exposed to culture medium). ((c) $n=7$ ) P-gp transport activity in GERP cells after exposure to 10 ng/mL TNF- $\alpha$ in combination with $5 \mathrm{ng} / \mathrm{mL}$ of the antibody against human TLR 4 for 24 hours compared to control. Data are expressed as mean \pm SEM. Significantly different compared to control $\left({ }^{* * *}: P<.001\right)$ or to TNF- $\left.\alpha{ }^{\# \#} ; P<.01\right)$. Treatment with H398 or anti-TLR4 alone showed no significant difference compared to control.

2.4. Western Blotting. Cells were harvested after exposure to different inflammatory mediators and lysed with $0.1 \%$ Triton X-100 supplemented with protease inhibitors (1 mM PMSF, $10 \mu \mathrm{M}$ E64, $1 \mu \mathrm{g} / \mathrm{mL}$ pepstatin, $5 \mu \mathrm{g} / \mathrm{mL}$ leupeptin and $1 \mu \mathrm{g} / \mathrm{mL}$ aprotinin) during 30 minutes on ice. The amount of protein in cell lysates was determined with the Bio-Rad protein assay (Bio-Rad Laboratories, Hercules, CA) using bovine serum albumin as standard and samples were subjected to Western blotting as described previously [17].

Samples were separated on a $6 \%$ sodium dodecylsulfate polyacrylamide gel and transferred to Hybond-C pure nitrocellulose membrane (Amersham, Buckinghamshire, UK). The membrane was incubated overnight at $4^{\circ} \mathrm{C}$ with the primary antibodies against iNOS $(1: 1000$, according to [18]), ABCB1/P-gp (1 : 200, C219, DakoCytomation,
Denmark), or $\beta$-actin ( $1: 10000$, Sigma-Aldrich) in Trisbuffered saline supplemented with $0.1 \%$ Tween-20 (TBS-T) and $1 \%$ non-fat dried milk.

Subsequently, the membranes were washed three times in TBS-T, blocked in TBS-T containing 5\% non-fat dried milk, washed three times in TBS-T again, and incubated with affinity-purified horseradish peroxidase-conjugated goat antirabbit IgG (Sigma-Aldrich) for iNOS or goat antimouse IgG (Sigma-Aldrich) for P-gp and $\beta$-actin diluted 1 : 5000 in TBS-T for 1 hour at room temperature. The washing steps were repeated, after which the membranes were visualized with enhanced chemiluminescence (Pierce Chemical, Rockford, IL). For semiquantification, the pixel intensity of the bands was measured using Scion Image version beta 4.02 for Windows (Scion Corporation, Frederick, $\mathrm{MD})$. 


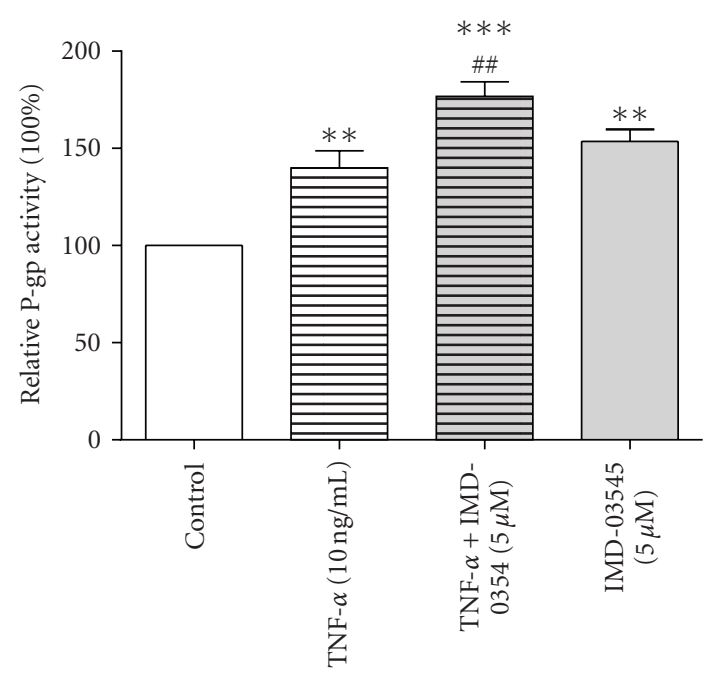

(a)

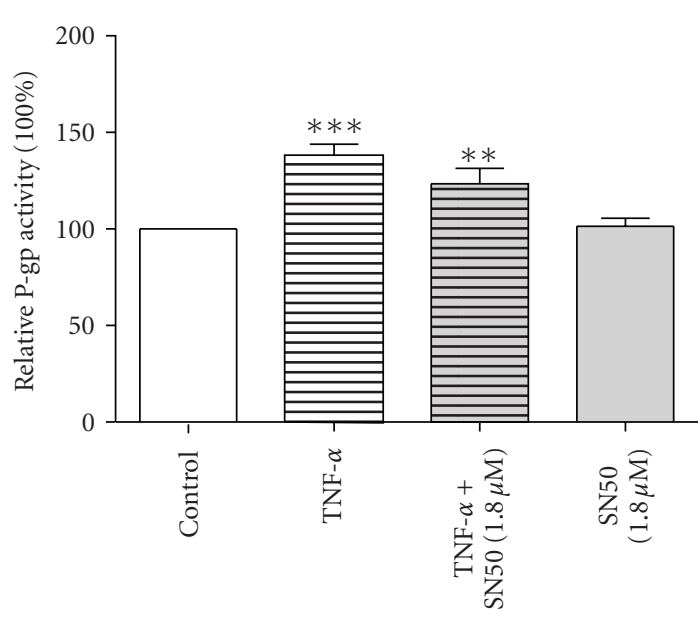

(b)

FIGURE 5: Role of NF- $\kappa$ B in modulation of P-gp activity in GERP cells. ((a) $n=4)$ P-gp transport activity in GERP cells after exposure to $10 \mathrm{ng} / \mathrm{mL}$ TNF- $\alpha$ in combination with $5 \mu \mathrm{M}$ of the selective IKK $\beta$ inhibitor IMD-0354 compared to control (cells exposed to culture medium). ((b) $n=7)$ P-gp transport activity in GERP cells after exposure to $10 \mathrm{ng} / \mathrm{mL}$ TNF- $\alpha$ in combination with $1.8 \mu \mathrm{M}$ of a cellpermeable inhibitor peptide that interferes with NF- $\kappa$ B nuclear translocation, SN50, for 24 hours compared to control. Data are expressed as mean \pm SEM. Significantly different compared to control cells $\left({ }^{* *} ; P<.01,{ }^{* * *}: P<.001\right)$ or to TNF- $\alpha\left({ }^{\# \#}: P<.001\right)$. Treatment with SN50 alone showed no, but with IMD-0354 alone did show significant difference compared to control.

2.5. Data Analysis. Values are given as mean \pm SEM. Analysis was performed using GraphPad Prism 4.03 for Windows (Graphpad Software Inc., San Diego, CA, USA) and SPSS (version 12.0.1 for Windows, Chicago, IL). Differences between the experimental groups were tested using one-way ANOVA with Bonferroni's correction or two-way repeated measurements ANOVA. A two-sided $P$ value $<.05$ was considered significantly different.

\section{Results and Discussion}

3.1. Effect of Inflammatory Mediators on P-gp Expression and Activity. Treatment of GERP cells with $10 \mu \mathrm{g} / \mathrm{mL}$ LPS and/or $10-100 \mathrm{ng} / \mathrm{mL}$ TNF- $\alpha$ for 24 hours resulted in an increase in P-gp activity (Figures $1(\mathrm{a})-1(\mathrm{c}), P<.05)$. As $10 \mathrm{ng} / \mathrm{mL}$ is a clinically relevant concentration [11] and a 10-fold higher TNF- $\alpha$ concentration or combination of TNF- $\alpha$ and LPS did not further increase P-gp activity, we used a concentration of $10 \mathrm{ng} / \mathrm{mL}$ TNF- $\alpha$ for additional experiments. In accordance, we also observed an upregulation in $A b c b 1 b$ expression after exposure to TNF- $\alpha$, LPS, or a combination of TNF- $\alpha$ and LPS (Figure $1(\mathrm{~d})$ ), which was accompanied by an increase in Pgp protein expression (Figure 1(e)), suggesting de novo P-gp synthesis. This finding is in agreement with previous studies in mice and rats in which the upregulation of renal P-gp was demonstrated after in vivo LPS exposure $[2,19,20]$.

3.2. P-gp Expression and Activity Also Independent of NO. We previously suggested that $\mathrm{P}-\mathrm{gp}$ is likely to be regulated by $\mathrm{NO}$ produced by iNOS, as coadministration of aminoguanidine reversed the induction in iNOS, reduced renal damage and attenuated the endotoxin-induced effects on its expression in rats [2]. In agreement, we show here that both iNOS mRNA (Figure 2(a), $P<.001$ ) and protein (Figure $2(\mathrm{~b})$ ) are upregulated when cells are exposed to LPS, either alone or in combination with TNF- $\alpha$. Treatment with TNF- $\alpha$ alone, however, only marginally induced NOSII mRNA, but had no effect on iNOS protein (Figures 2(a), and 2(b)).

To determine the NO-dependency of the upregulation of P-gp, GERP cells were co-treated with the NO-scavenger PTIO or exposed to the NO donor SNP. Indeed, the $\mathrm{P}$-gp efflux activity was not significantly different from control anymore after co-treatment with PTIO (Figure 2(c)). Remarkably, SNP, did not affect $A b c b 1 b$ (data not shown) and P-gp protein expression (Figure 2(d)) and its activity was slightly, though not significantly, upregulated after 1 hour exposure and 5 hours recovery (Figure 2(e)). Prolonged exposure times to SNP resulted in cytotoxicity (data not shown). This is in contrast with previous findings demonstrating that NO, released by the NO donor S-nitroso-Nacetylpenicillamine, was able to upregulate $\mathrm{P}$-gp expression in the human $\mathrm{CaCo} 2$ cell line [21]. However, SNP produces besides NO also iron and cyanide [22], so it is not clear whether only effects of $\mathrm{NO}$ on P-gp expression and activity were measured. In contrast to LPS, our findings indicate that P-gp signaling seems largely NO-independent after exposure to TNF- $\alpha$. In addition, this signaling pathway may be dependent on the type of cytokine as NO mediated increased P-gp activity after stimulation with interferon$\gamma$ [21]. Furthermore, it was recently demonstrated that in vivo inhibition of NOS and subsequent $\mathrm{NO}$ production with L-NAME did not affect blood-brain barrier P-gp function during endotoxemia [23], which contradicts with 


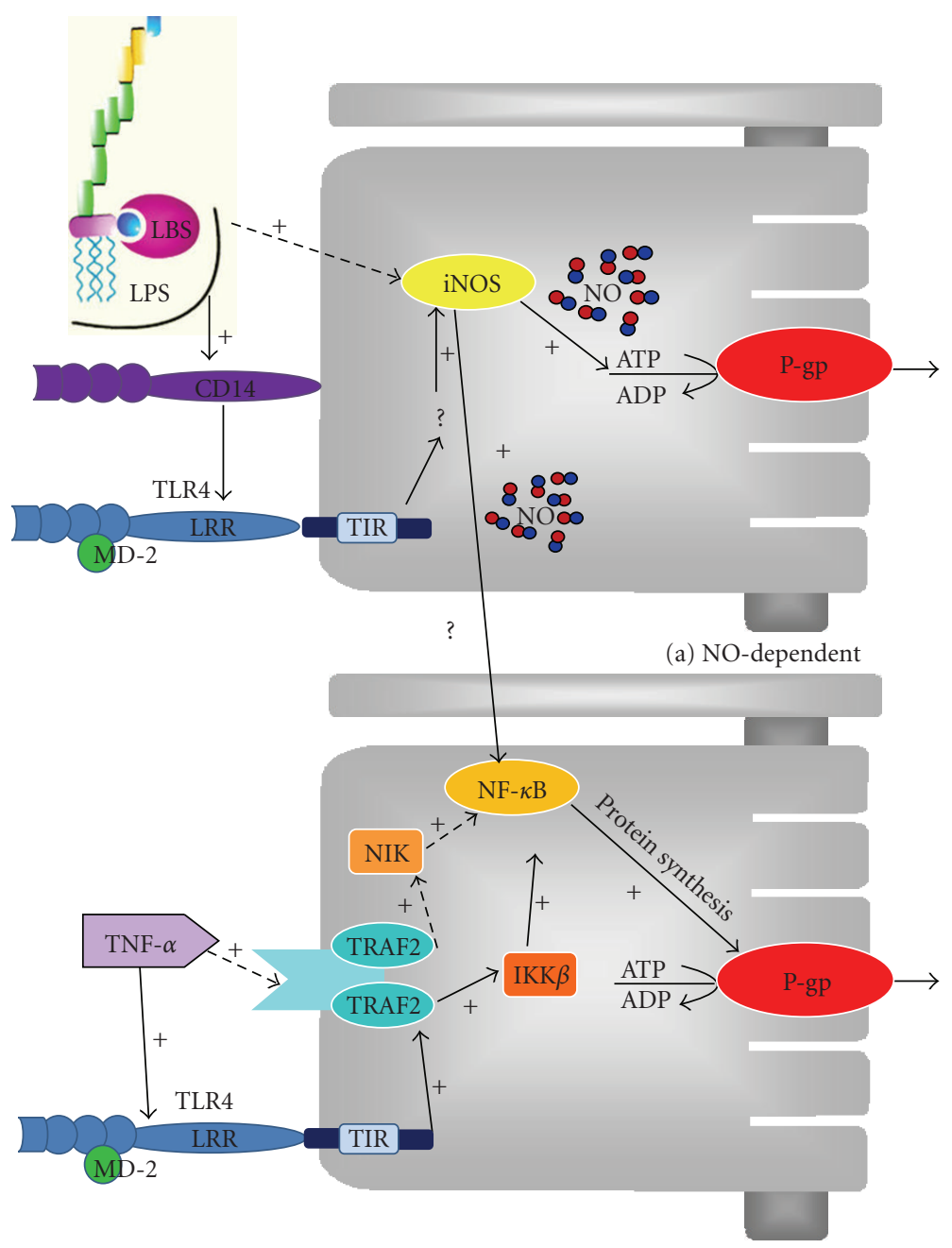

(b) NO-independent

FIGURE 6: Scheme illustrating the proposed sequence of events by which inflammatory mediators increase P-gp-mediated transport in GERP cells. (a) NO-dependent pathway after exposure to LPS directly or indirectly via TLR4. (b) NO-independent pathway after exposure to TNF- $\alpha$. This pathway involves the activation of NF- $\kappa \mathrm{B}$ inducing kinase (NIK) by TNF receptor associated factor family (TRAF) 2 and, consequently, the activation of NF- $\kappa \mathrm{B}$ or the activation of TLR4 leading to the activation of IKK $\beta$ by TRAF2 and consequently the activation of NF- $\kappa \mathrm{B}$. TIR; toll-IL-1R domain in TLR, LRR, leucine rich repeats domain in TLR.

previous in vitro findings in isolated rat brain capillaries $[7,8]$.

3.3. Regulation of P-gp Activity by TNF- $\alpha$. To dissect the signaling pathway through which exposure to TNF- $\alpha$ increased P-gp expression and activity we used various pharmacological agents. Since NO is a well-known activator of sGC, which is in turn involved in the PKC signalling pathway [5], the effects of the sGC inhibitor ODQ (Figure 3(a)) and the PKC inhibitor BIM (Figure 3(b)) on P-gp activity were examined. Importantly, none of the two substances could prevent the upregulation of P-gp caused by TNF- $\alpha$, suggesting that a novel pathway mediates P-gp activity in GERP cells and/or that the NO-sGC-PKC pathway is not activated in our cell line. This finding is in contrast with previous studies using killifish renal proximal tubules and brain capillary membranes [4-7].
LPS signals through toll-like receptor-4 (TLR-4) and TNF- $\alpha$ mediates their effect by binding to TNFR1 (p55) and TNFR2 (p75), which are known to be expressed in the kidney and their expression patterns are modulated during immune-mediated and ischemic renal injury [24, 25]. Figure 4(a) shows that TNFR1 and TLR4 are expressed in the GERP cell line, whereas TNFR2 expression could not be detected. To confirm the results of the PCR analysis, we used inhibitors of and/or antibodies against TNFR1 (H398, Figure 4(b)) and TLR4 (anti-TLR4, Figure 4(c)) and determined P-gp activity. Exposure to H398 could not prevent the upregulation of P-gp by TNF- $\alpha$, suggesting that although TNFR1 is expressed in GERP cells it may not be involved in P-gp regulation (Figure 4(b)). Many cell types require cooperation between TNFR1 and TNFR2 to generate TNF responses [26], and the absence of TNFR2 in our cells could explain why TNFR1 did not affect the regulation of P-gp activity by TNF- $\alpha$. On the other hand, 
inhibition of TLR4 resulted in an attenuation in P-gp activity (Figure 4(c)), and an involvement of this toll-like receptor is in agreement with previous findings in brain capillaries [8].

Since the transcription factor NF- $\kappa$ B is the downstream effector of TNF- $\alpha$ signalling in brain capillaries [7], we wondered whether the same holds true for the regulation of P-gp activity by TNF- $\alpha$ in this proximal tubular cell line. GERP cells were exposed for 24 hours to the selective I kappa B kinase (IKK) $\beta$ inhibitor, IMD-0354 (Figure 5(a)), or SN50 (Figure 5(b)). Remarkably, IMD-0354 alone gave a significant upregulation of P-gp activity compared to control cells (Figure 5(a), $P<.01$ ), indicating that the compound itself has an effect on P-gp. An alternative explanation would be that IMD-0354 may have potentiated the responses to TNF- $\alpha$ and, therefore, NF- $\kappa$ B inhibits P-gp activity and blockade of nuclear translocation of this transcription factor leads to enhancement of TNF- $\alpha$ induction. Exposing the cells to the combination of SN50, a cell-permeable inhibitor peptide that interferes with NF$\kappa \mathrm{B}$ nuclear translocation, and TNF- $\alpha$ slightly reversed the increase in P-gp activity upon TNF- $\alpha$ treatment (Figure 5(b) NS), suggesting a role for the transcription factor. Although higher SN50 concentrations have been used before [7] this was not feasible in our cell system due to solubility problems. Hence, a role for NF- $\kappa$ B was demonstrated previously after detrimental stimuli. Thevenod et al. showed that an upregulation of P-gp by NF- $\kappa \mathrm{B}$ is potentially important for protecting renal proximal tubule cells from apoptosis induced by cadmium- and reactive oxygen species (ROS) [9]. In addition, an increase in P-gp expression and/or activity by TNF- $\alpha$ was reported for primary rat hepatocytes [27], a rat hepatoma cell line [28] and mouse liver [29], which are also NF- $\kappa$ B dependent [28]. Furthermore, an NF$\kappa \mathrm{B}$ binding site was found in the promoter region of the Abcb1 gene [30]. Therefore, we suggest that NF- $\kappa$ B might have a central role in the signal transduction mechanism and could be involved in two distinct signalling pathways of P-gp. This nuclear factor is probably activated directly by proinflammatory cytokines and NO, and indirectly via TLR4. However, more research is needed to further unravel the regulation mechanism of P-gp in the GERP cell line and the inflammatory response on the activity of the efflux pump.

\section{Conclusions}

In accordance with previous rat endotoxemia studies, the upregulation of P-gp expression and activity after exposure to LPS in combination with TNF- $\alpha$ in the cultured renal proximal tubule cells are under influence of NO produced by iNOS. On the other hand, the signaling pathway of TNF- $\alpha$ alone leading to P-gp upregulation seems to involve TLR4 activation and NF- $\kappa \mathrm{B}$ translocation, which results in de novo synthesis of P-gp. Figure 6 summarizes the sequence of events. Our findings indicate that at least two different pathways regulate P-gp in renal proximal tubule cells during endotoxemia.

\section{Acknowledgment}

The first and last authors were supported by a grant from the Netherlands Organisation for Scientific Research (NWO).

\section{References}

[1] A. H. Schinkel and J. W. Jonker, "Mammalian drug efflux transporters of the ATP binding cassette (ABC) family: an overview," Advanced Drug Delivery Reviews, vol. 55, no. 1, pp. 3-29, 2003.

[2] S. Heemskerk, A. van Koppen, L. van den Broek, et al., "Nitric oxide differentially regulates renal ATP-binding cassette transporters during endotoxemia," Pflugers Archiv European Journal of Physiology, vol. 454, no. 2, pp. 321-334, 2007.

[3] M. Huls, J. J. van den Heuvel, H. B. Dijkman, F. G. M. Russel, and R. Masereeuw, "ABC transporter expression profiling after ischemic reperfusion injury in mouse kidney," Kidney International, vol. 69, no. 12, pp. 2186-2193, 2006.

[4] S. Notenboom, D. S. Miller, P. Smits, F. G. M. Russel, and R. Masereeuw, "Role of NO in endothelin-regulated drug transport in the renal proximal tubule," American Journal of Physiology, vol. 282, no. 3, pp. F458-F464, 2002.

[5] S. Notenboom, D. S. Miller, P. Smits, F. G. M. Russel, and R. Masereeuw, "Involvement of guanylyl cyclase and cGMP in the regulation of Mrp2-mediated transport in the proximal tubule," American Journal of Physiology, vol. 287, no. 1, pp. F33-F38, 2004.

[6] A. M. S. Hartz, B. Bauer, G. Fricker, and D. S. Miller, "Rapid regulation of P-glycoprotein at the blood-brain barrier by endothelin-1," Molecular Pharmacology, vol. 66, no. 3, pp. 387-394, 2004.

[7] B. Bauer, A. M. S. Hartz, and D. S. Miller, "Tumor necrosis factor $\alpha$ and endothelin-1 increase p-glycoprotein expression and transport activity at the blood-brain barrier," Molecular Pharmacology, vol. 71, no. 3, pp. 667-675, 2007.

[8] A. M. S. Hartz, B. Bauer, G. Fricker, and D. S. Miller, "Rapid modulation of P-glycoprotein-mediated transport at the blood-brain barrier by tumor necrosis factor- $\alpha$ and lipopolysaccharide," Molecular Pharmacology, vol. 69, no. 2, pp. 462-470, 2006.

[9] F. Thévenod, J. M. Friedmann, A. D. Katsen, and I. A. Hauser, "Up-regulation of multidrug resistance P-glycoprotein via nuclear factor- $\kappa \mathrm{B}$ activation protects kidney proximal tubule cells from cadmium- and reactive oxygen species-induced apoptosis," The Journal of Biological Chemistry, vol. 275, no. 3, pp. 1887-1896, 2000.

[10] F. M. van de Water, J. M. Boleij, J. G. P. Peters, F. G. M. Russel, and R. Masereeuw, "Characterization of P-glycoprotein and multidrug resistance proteins in rat kidney and intestinal cell lines," European Journal of Pharmaceutical Sciences, vol. 30, no. 1, pp. 36-44, 2007.

[11] J. M. Cavaillon, M. Adib-Conquy, C. Fitting, C. Adrie, and D. Payen, "Cytokine cascade in sepsis," Scandinavian Journal of Infectious Diseases, vol. 35, no. 9, pp. 535-544, 2003.

[12] F. Tiberghien and F. Loor, "Ranking of P-glycoprotein substrates and inhibitors by a calcein-AM fluorometry screening assay," Anti-Cancer Drugs, vol. 7, no. 5, pp. 568-578, 1996.

[13] S. Heemskerk, P. Pickkers, M. P. Bouw, et al., "Upregulation of renal inducible nitric oxide synthase during human endotoxemia and sepsis is associated with proximal tubule injury," Clinical journal of the American Society of Nephrology, vol. 1, no. 4, pp. 853-862, 2006. 
[14] F. M. van de Water, F. G. M. Russel, and R. Masereeuw, "Regulation and expression of endothelin-1 (ET-1) and ETreceptors in rat epithelial cells of renal and intestinal origin," Pharmacological Research, vol. 54, no. 6, pp. 429-435, 2006.

[15] Y. Li, A. Ji, E. Weihe, and M. K.-H. Schäfer, "Cellspecific expression and lipopolysaccharide-induced regulation of tumor necrosis factor $\alpha(\mathrm{TNF} \alpha)$ and TNF receptors in rat dorsal root ganglion," Journal of Neuroscience, vol. 24, no. 43, pp. 9623-9631, 2004.

[16] H. Wissel, C. Schulz, P. Koehne, E. Richter, M. Maass, and M. Rüdiger, "Chlamydophila pneumoniae induces expression of Toll-like receptor 4 and release of TNF- $\alpha$ and MIP-2 via an NF$\kappa \mathrm{B}$ pathway in rat type II pneumocytes," Respiratory Research, vol. 6, article 51, 2005.

[17] S. Notenboom, A. C. Wouterse, B. Peters, et al., "Increased apical insertion of the multidrug resistance protein 2 (MRP2/ABCC2) in renal proximal tubules following gentamicin exposure," Journal of Pharmacology and Experimental Therapeutics, vol. 318, no. 3, pp. 1194-1202, 2006.

[18] T. A. Vos, A. S. H. Gouw, P. A. Klok, et al., "Differential effects of nitric oxide synthase inhibitors on endotoxin-induced liver damage in rats," Gastroenterology, vol. 113, no. 4, pp. 13231333, 1997.

[19] G. Hartmann, V. Vassileva, and M. Piquette-Miller, "Impact of endotoxin-induced changes in P-glycoprotein expression on disposition of doxorubicin in mice," Drug Metabolism and Disposition, vol. 33, no. 6, pp. 820-828, 2005.

[20] S. Heemskerk, A. C. Wouterse, F. G. M. Russel, and R. Masereeuw, "Nitric oxide down-regulates the expression of organic cation transporters (OCT) 1 and 2 in rat kidney during endotoxemia," European Journal of Pharmacology, vol. 584, no. 2-3, pp. 390-397, 2008.

[21] S. G. Dixit, B. Zingarelli, D. J. Buckley, A. R. Buckley, and G. M. Pauletti, "Nitric oxide mediates increased P-glycoprotein activity in interferon- $\gamma$-stimulated human intestinal cells," American Journal of Physiology, vol. 288, no. 3, pp. G533G540, 2005.

[22] H. J. Kim, I. Tsoy, K. P. Min, et al., "Iron released by sodium nitroprusside contributes to heme oxygenase-1 induction via the cAMP-protein kinase A-mitogen-activated protein kinase pathway in RAW 264.7 cells," Molecular Pharmacology, vol. 69, no. 5, pp. 1633-1640, 2006.

[23] M. A. Salkeni, J. L. Lynch, T. Otamis-Price, and W. A. Banks, "Lipopolysaccharide impairs blood-brain barrier Pglycoprotein function in mice through prostaglandin- and nitric oxide-independent pathways," Journal of Neuroimmune Pharmacology, vol. 4, no. 2, pp. 276-282, 2009.

[24] R. S. Al-Lamki, J. Wang, J. N. Skepper, S. Thiru, J. S. Pober, and J. R. Bradley, "Expression of tumor necrosis factor receptors in normal kidney and rejecting renal transplants," Laboratory Investigation, vol. 81, no. 11, pp. 1503-1515, 2001.

[25] P. Chowdhury, S. H. Sacks, and N. S. Sheerin, "Toll-like receptors TLR2 and TLR4 initiate the innate immune response of the renal tubular epithelium to bacterial products," Clinical and Experimental Immunology, vol. 145, no. 2, pp. 346-356, 2006.

[26] A. P. Grech, S. Gardam, T. Chan, et al., "Tumor necrosis factor receptor 2 (TNFR2) signaling is negatively regulated by a novel, carboxyl-terminal TNFR-associated factor 2 (TRAF2)binding site," The Journal of Biological Chemistry, vol. 280, no. 36, pp. 31572-31581, 2005.

[27] K. I. Hirsch-Ernst, C. Ziemann, H. Foth, D. Kozian, C. Schmitz-Salue, and G. F. Kahl, "Induction of mdrlb mRNA and P-glycoprotein expression by tumor necrosis factor alpha in primary rat hepatocyte cultures," Journal of Cellular Physiology, vol. 176, no. 3, pp. 506-515, 1998.

[28] J. E. Ros, J. D. Schuetz, M. Geuken, et al., "Induction of Mdr1b expression by tumor necrosis factor- $\alpha$ in rat liver cells is independent of $\mathrm{p} 53$ but requires NF- $\kappa \mathrm{B}$ signaling," Hepatology, vol. 33, no. 6, pp. 1425-1431, 2001.

[29] G. Hartmann, A. K. Y. Cheung, and M. Piquette-Miller, "Inflammatory cytokines, but not bile acids, regulate expression of murine hepatic anion transporters in endotoxemia," Journal of Pharmacology and Experimental Therapeutics, vol. 303, no. 1, pp. 273-281, 2002.

[30] G. Zhou and M. T. Kuo, "NF- $\kappa$ B-mediated induction of mdr1b expression by insulin in rat hepatoma cells," The Journal of Biological Chemistry, vol. 272, pp. 15174-15183, 1997. 

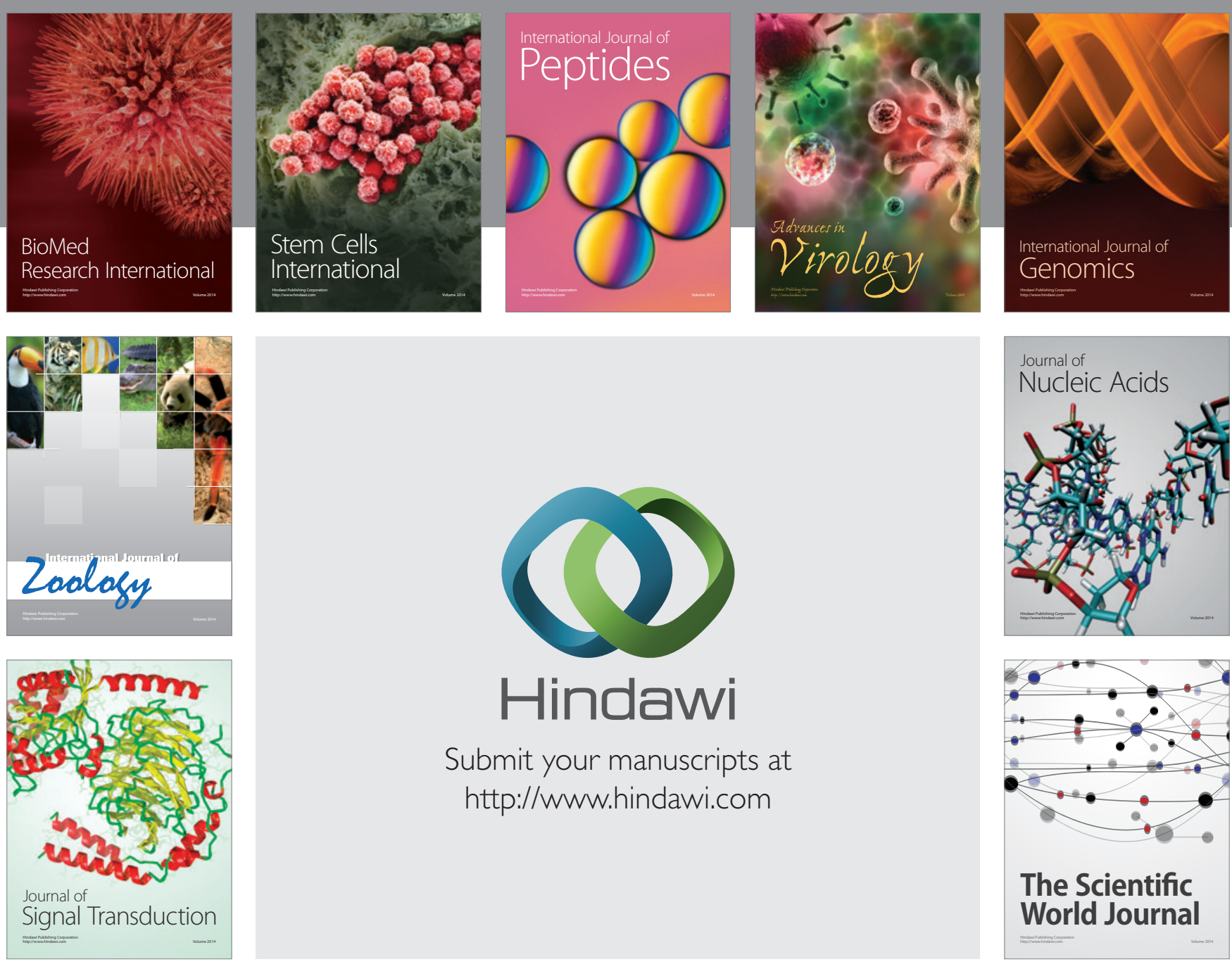

Submit your manuscripts at

http://www.hindawi.com
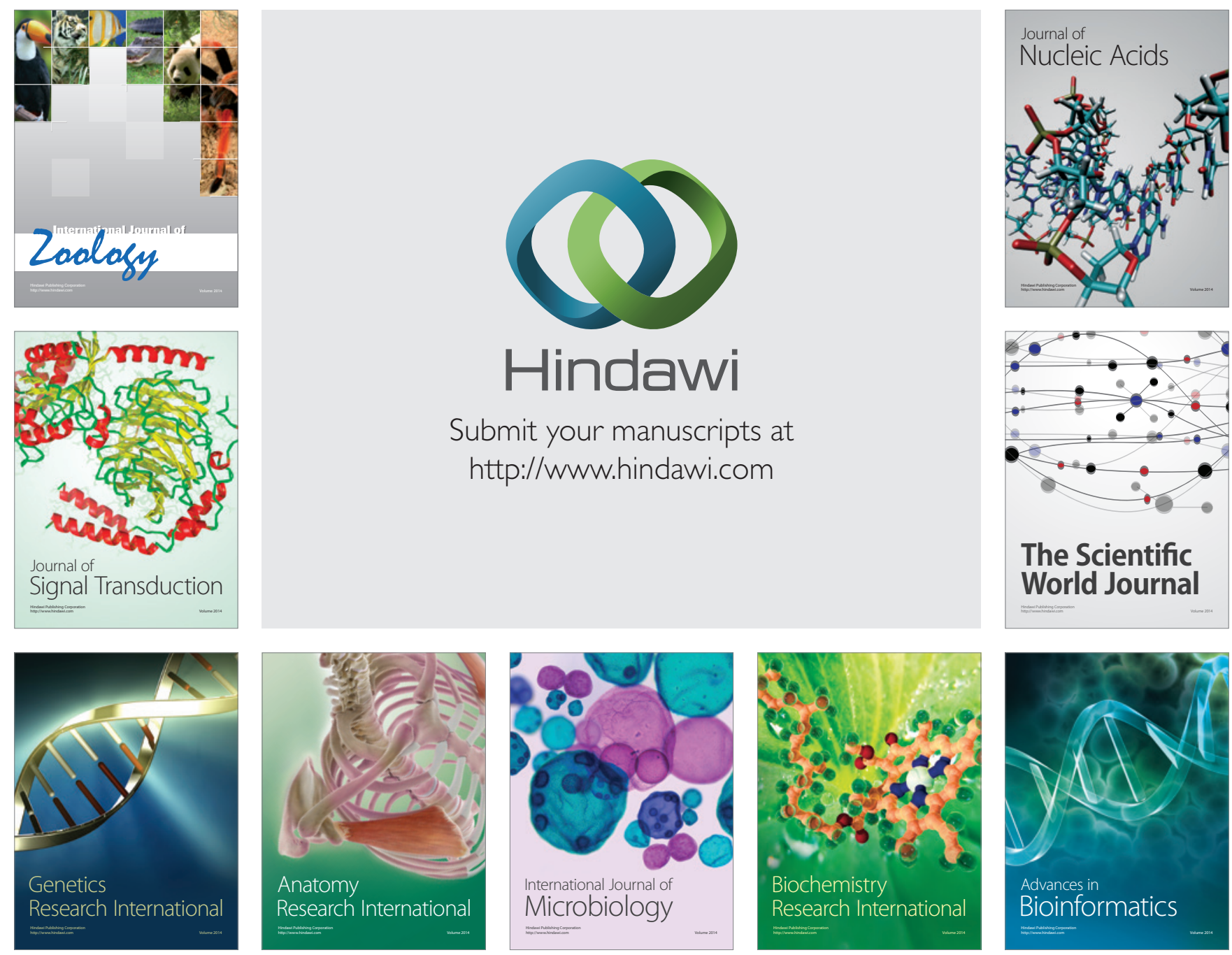

The Scientific World Journal
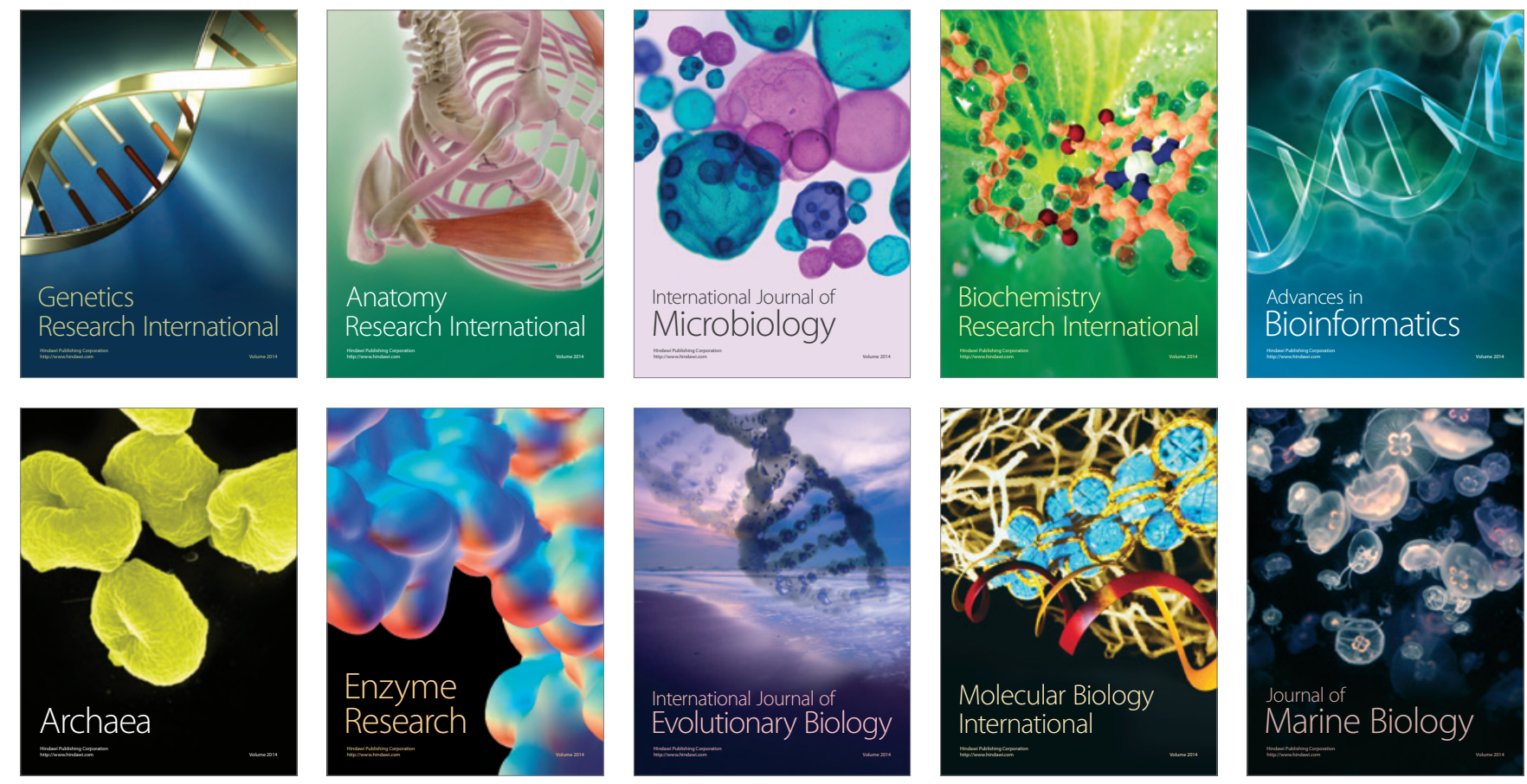